\title{
PRODUÇÃO DE BIOMASSA EM CLONES DE PALMA FORRAGEIRA SOB REGIME DE SEQUEIRO E IRRIGADO NO SEMIÁRIDO BAIANO.
}

\author{
Cássio Gyovanne de Aquino Amorim; ; Adriana Rodrigues Passos ${ }^{2}$; Mariana \\ Santos de Jesus ${ }^{3}$ \\ 1- Bolsista FAPESB, Graduando em Agronomia/ Universidade estadual de Feira de Santana, e-mail: \\ cassiogyovanneagro@ hotmail.com \\ 2-Orientadora, Departamento de biologia, Professora doutora/ Universidade Estadual de Feira de Santana, e-mail: \\ adrianarpassos@yahoo.com.br \\ 3. Participante da pesquisa, Doutoranda - RGV/ Universidade Estadual de Feira de Santana, e-mail: \\ maryanamell@gmail.com
}

PALAVRAS-CHAVE: Opuntia fícus-indica L.; Produtividade; Irrigação.

\section{INTRODUÇÃO}

A palma forrageira é nativa do México (Opuntia fícus-indica (L.) Mill) (ReyesAguero et al., 2005) e foi introduzida no Brasil por volta de 1880, no estado de Pernambuco, através de sementes importadas do Texas - Estados Unidos, apresentando boa adaptação no semiárido brasileiro (Silva e Carvalho, 2006). A espécie pertence à ordem Opuntiales e família das cactáceas. Nessa família, existem 178 gêneros com cerca de 2.000 espécies conhecidas. Ademais, em função dos gêneros Opuntia, espécie Opuntia ficus-indica Mill e Nopalea, espécie Nopalea cochenillifera Salm - Dyck serem as mais utilizadas como forrageiras, em regiões de baixo índice pluviométrico, em especial o semiárido nordestino, compreendem as palmas de maior importância (Silva e Carvalho, 2006; Santos et al., 2006).

De composição química variável de acordo com a espécie, idade, época do ano e tratos culturais, a palma é um alimento energético, rico em carboidratos não-fibrosos e alto teor de cinzas. Entretanto, apresenta baixos teores de proteína bruta, em média 5\%, e fibra em detergente neutro (Ferreira, 2005). Do ponto de vista nutricional, a palma forrageira contêm alto teor de umidade (cerca de $85 \%$ ), alta digestibilidade in vitro (cerca de $75 \%$ ) e alto conteúdo de vitamina A.

Segundo o Instituto Brasileiro de Geografia e Estatística (IBGE) (2014), a região nordeste do Brasil possui um rebanho efetivo de bovinos, ovinos e caprinos que representam, respectivamente, $13,8 \%, 57 \%$ e $91,6 \%$ do rebanho nacional. E, levando em consideração que $70 \%$ do nordeste brasileiro abrange o clima semiárido, onde as médias de precipitação pluviométrica variam de 300 a $800 \mathrm{~mm}$ anuais, com maior volume de chuvas na estação úmida, que dura cerca de três a quatro meses, gerando déficit hídrico durante o restante do ano (Araújo Filho et. al., 1985), faz-se necessário o estabelecimento de estratégias de cultivo para atender a demanda crescente dos criadores em épocas de extrema estiagem.

Dessa maneira, a utilização do sistema de irrigação por gotejamento, no plantio de palma forrageira, poderá ser utilizado como alternativa para manter uma alta produção de biomassa durante todo o ano, e em especial nos períodos de estiagem, havendo assim a disponibilidade de forragem para os rebanhos dessas regiões

\section{MATERIAL E MÉTODOS}


Os experimentos foram conduzidos na Fazenda Canela, localizada no município de Lapão, Bahia, de coordenadas $11^{\circ} 26^{\prime} 7.8^{\prime}$ ' S, 41 48' 51.46” W, estando a 806 m de altitude. Para implantação da área experimental foram utilizados clones selecionados por Oliveira (2010), com utilização de quatro genótipos de palma forrageira pertencentes à palma gigante (Opuntia ficus-indica Mill.), sendo um deles testemunha (IPA20) em regime de sequeiro e irrigado.

O delineamento experimental foi em blocos casualisados, com quatro repetições. Cada bloco apresentou seis fileiras (sendo duas bordaduras) e cada fileira com quatro plantas. No plantio foi utilizado um cladódio por cova, na posição vertical, com a porção cortada voltada para o solo, na profundidade a evitar o tombamento, obedecendo ao espaçamento de 1,0 x 0,5 m (fileiras e plantas). Para a implantação do experimento realizou-se análise de solo, correções necessárias e preparo da área (subsolagem e gradagem). A coleta do material foi realizada na Unidade Experimental Horto Florestal (Feira de Santana), e o plantio foi estabelecido no mês de agosto de 2015.

Para o regime irrigado, utilizou-se o sistema de gotejamento com mangueira irritec com válvulas dispostas em intervalos de $30 \mathrm{~cm}$, com vazão por válvula de 1,6 L $\mathrm{h}^{-1}$. A irrigação foi realizada uma vez por semana por um período de três horas. Posteriormente, foram realizadas duas roçagens e duas capinas da área cultivada para manutenção do plantio.

A determinação da massa verde e massa seca das plantas foram realizadas oito meses após o plantio. As plantas foram coletadas e pesadas com auxilio de balança digital. Posteriormente, os cladódios foram submetidos à secagem em estufa de ventilação forçada a $65^{\circ} \mathrm{C}$, por um período de quinze dias para determinação da massa seca por diferença de peso. As estimativas de produção de matéria verde e matéria seca por hectare foram obtidas com seguintes expressões, respectivamente: (MVT*10000)/8

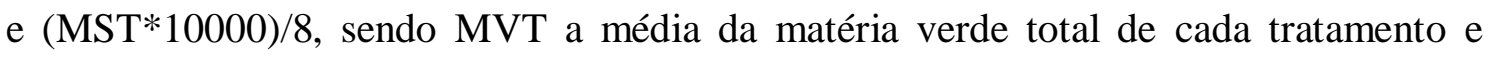
MST a média da matéria seca total de cada tratamento.

Os dados coletados foram submetidos à análise de variância, utilizando-se o teste F, e a comparação das médias pelo teste Scott-Knott a $1 \%$ de probabilidade $(\mathrm{p}<0,01)$, utilizando o programa estatístico Sisvar 5.3 (FERREIRA, 2008).

\section{RESULTADOS E DISCUSSÃO}

$\mathrm{Na}$ tabela 1 foram apresentados os valores de quadrado médio e seus níveis de significância para os descritores que determinaram a produtividade do experimento. Dentro da fonte de variação dos sistemas, os descritores MV (5\% de probabilidade), \%MS e PRODMV (1\% de probabilidade) apresentaram diferenças significativas. Para MS e PRODMS os dados não tiveram diferença significativa. Para as fontes de variação genótipo e bloco apenas o descritor \%MS não apresentou diferença significativa. Para a interação GxS (genótipo x sistema) somente o descritor \%_MS foi significativo a 5\% de probabilidade.

O coeficiente de variação é interpretado como a variabilidade dos dados em relação à média. Quanto menor o $\mathrm{CV}$ mais homogêneo é o conjunto de dados. Segundo Pimentel e Gomes (1985), valores menores que $10 \%$ são considerados baixos, entre $10 \%$ e $20 \%$ médios, entre $20 \%$ e $30 \%$ altos, e maiores que $30 \%$ muito altos. Foram 
observados, no presente trabalho, valores de $\mathrm{CV}(\%)$ altos, exceto para MS que apresentou baixo valor para este parâmetro.

Tabela 1. Análise de variância e coeficientes de variação experimental para os caracteres matéria verde (MV) $(\mathrm{g})$, matéria seca $(\mathrm{MS})(\mathrm{g})$, porcentagem de matéria seca (\%MS), produtividade de matéria verde (PRODMV) (MV/Ha) e produtividade de matéria seca (PRODMS) (MS/Ha), avaliadas em quatro clones de palma gigante (Opuntia ficus-indica Miil) cultivados no semiárido baiano, sob diferentes sistemas de cultivo (irrigado e sequeiro), e avaliados ao final do experimento (8 meses).

\begin{tabular}{l|llllll}
\hline \multirow{2}{*}{$\boldsymbol{F} \boldsymbol{V}$} & \multicolumn{6}{|c}{ QUADRADO MÉDIO } \\
\cline { 2 - 7 } Sistema & GL & MV & MS & $\%$ MS & PRODMV & PRODMS \\
Genótipo & 1 & $227711.26^{*}$ & $5.19^{\mathrm{ns}}$ & $632.87^{* *}$ & $35582668.38^{* *}$ & $2075.45^{\mathrm{ns}}$ \\
Bloco & 3 & $24030.00^{* *}$ & $136.85^{* *}$ & $0.85^{\mathrm{ns}}$ & $3754396.16^{*}$ & $54732.98^{*}$ \\
G x S & 3 & $50819.66^{* *}$ & $178.90^{*}$ & $2.63^{\mathrm{ns}}$ & $7940436.84^{* *}$ & $71545.39^{* *}$ \\
Resíduo & 21 & $713547.55^{\mathrm{ns}}$ & $72.45^{\mathrm{ns}}$ & $4.87^{*}$ & $2272765.87^{\mathrm{ns}}$ & $28985.12^{\mathrm{ns}}$ \\
CV (\%) & & 38.61 & 36.31 & 1.57 & 1115562.23 & 14526.66 \\
\hline
\end{tabular}

$\mathrm{ns}=$ Não significativo, $*=$ Significativo no nível de $5 \%$ de probabilidade pelo teste $\mathrm{F}$, ** = Significativo no nível de $1 \%$ de probabilidade pelo teste F.

$\mathrm{Na}$ Tabela 2, são apresentados valores para os descritores que determinaram a produtividade para a fonte de variação dos diferentes sistemas utilizados. Observou-se a formação de grupos distintos, com superioridade dos clones em sistema irrigado, para os caracteres MV, \%MS e PRODMV. Entretanto, MS e PRODMS não expressaram variação quando submetidos aos diferentes sistemas de cultivos, demonstrando que caracteres relacionados a matéria seca apresentam maior estabilidade mesmo em condições de extrema estiagem, resultado de grande relevância quando se considera que a palma é utilizada, na sua grande maioria, por produtores que não dispõe de recursos financeiros para utilização desta tecnologia.

Tabela 2. Valores médios para matéria verde (MV) (g), matéria Seca (MS) (g), porcentagem de matéria seca (\%MS), produtividade de matéria verde (PRODMV) (MV/Ha) e produtividade de matéria seca (PRODMS) (MS/Ha) avaliadas em clones de palma gigante (Opuntia ficus-indica Miil) cultivados no semiárido baiano sob diferentes sistemas (irrigado e sequeiro).

\begin{tabular}{llllll}
\hline SISTEMA & \multicolumn{5}{c}{ VARIÁVEIS } \\
\cline { 2 - 6 } & MV & MS & \%MS & PRODMV & PRODMS \\
IRRIGADO & $303.20 \mathrm{~A}$ & $18.93 \mathrm{~A}$ & $6.11 \mathrm{~B}$ & $3790.11 \mathrm{~A}$ & $394.78 \mathrm{~A}$ \\
SEQUEIRO & $134.49 \mathrm{~B}$ & $19.74 \mathrm{~A}$ & $15.00 \mathrm{~A}$ & $1681.12 \mathrm{~B}$ & $378.67 \mathrm{~A}$ \\
\hline
\end{tabular}

Médias seguidas pelas mesmas letras maiúsculas na mesma coluna constituem grupo estatisticamente homogêneo pelo teste de Scott-Knott ao nível de 5\% de significância.

Na tabela 3, são apresentados os valores médios para as características que refletem a produtividade nos três clones avaliados. Houve a formação de grupos distintos para maioria dos caracteres. Nestes, os clones V50 e V6 se destacaram, 
apresentando os maiores valores em relação a testemunha (IPA20) e V4, com exceção da \%MS em que não se observaram diferenças significativas .

Tabela 3. Valores médios para matéria verde (MV) (g), matéria Seca (MS) (g), porcentagem de matéria seca (\%MS), produtividade de matéria verde (PRODMV) (MV/Ha) e produtividade de matéria seca (PRODMS) (MS/Ha) avaliadas em quatro clones de palma gigante (Opuntia ficus-indica Miil) cultivados no semiárido baiano.

\begin{tabular}{l|lllll}
\hline \multirow{2}{*}{ CLONES } & \multicolumn{5}{|c}{ VARIÁVEIS } \\
\cline { 2 - 6 } & MV & MS & $\%$ MS & PRODMV & PRODMS \\
V4 & $190.66 \mathrm{~B}$ & $17.00 \mathrm{~B}$ & $10.15 \mathrm{~A}$ & $2383.24 \mathrm{~B}$ & $340.09 \mathrm{~B}$ \\
V50 & $156.81 \mathrm{~B}$ & $14.71 \mathrm{~B}$ & $10.95 \mathrm{~A}$ & $1960.30 \mathrm{~B}$ & $294.28 \mathrm{~B}$ \\
V6 & $276.19 \mathrm{~A}$ & $23.22 \mathrm{~A}$ & $10.57 \mathrm{~A}$ & $3452.39 \mathrm{~A}$ & $464.39 \mathrm{~A}$ \\
& $251.72 \mathrm{~A}$ & $22.40 \mathrm{~A}$ & $10.53 \mathrm{~A}$ & $3146.52 \mathrm{~A}$ & $448.14 \mathrm{~A}$ \\
\hline
\end{tabular}

Médias seguidas pelas mesmas letras maiúsculas na mesma coluna constituem grupo estatisticamente homogêneo pelo teste de Scott-Knott ao nível de 5\% de significância.

\section{CONSIDERAÇÕES FINAIS}

As plantas submetidas ao sistema irrigado apresentaram maior produção de biomassa, em relação ao sistema de sequeiro;

Os genótipos V50 e V6 se destacaram com as melhores médias quanto a produtividade, se enquadrando nos melhores grupos, demonstrando superioridade em relação ao testemunho (IPA20) e o clone V4;

\section{REFERÊNCIAS}

ARAÚJO FILHO, J. A. Manipulação da vegetação lenhosa da caatinga para fins pastoris. Sobral: EMBRAPA - CNPC, 1985.

FERREIRA, M.A. Palma forrageira na alimentação de bovinos leiteiros. Recife: UFRPE, Imprensa Universitária, 68 p., 2005.

FERREIRA, D. F. Sisvar: um programa para análises e ensino de estatística. Revista Symposium, Lavras, v. 6, p.36-41, 2008.

IBGE - Instituto Brasileiro de Geografia e Estatística - Censo agropecuário 2014. Acesso em: 29 mar. 2016.

REYES-AGUERO, J.A.; AGUIRRE-RIVERA, J.R.; HERNÁNDEZ, H.M. Notas sisteméticas y descripción detallada de Opuntia ficus-indica (L) Mill. (Cactáceae). Agrociência, v. 39, n. 4, p. 395-408, 2005.

SIlvA, F. C. C.; CARVAlHO, L. Palma Forrageira (Opuntia Fícus- Indica Mill) como alternativa na alimentação de ruminantes. Revista Eletrônica de VeterináriaREDVET, Vol. VII nº 10, Out. 2006. 